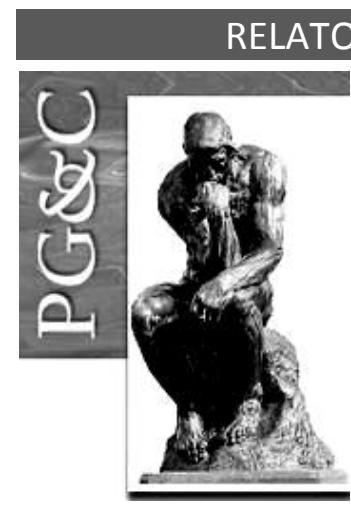

\title{
O PAPEL DA COMUNICAÇÃO NA GESTÃO DO CONHECIMENTO: ASPECTOS RELEVANTES E ESTÍMULO A NOVAS PESQUISAS
}

\author{
Ângela Pizzaia \\ Mestre em Gestão do Conhecimento pelo Centro Universitário de \\ Maringá, Brasil. Professora do Centro Universitário de Maringá, Brasil. \\ E-mail: angelapizzaia@hotmail.com \\ Paulo Marcelo Ferraresi Pegino \\ Doutor em Administração de Empresas pela Fundação Getúlio Vargas \\ Brasil. Professor da Universidade Federal do Paraná, Brasil. \\ E-mail: pferraresi@gmail.com \\ Júlio Ernesto Colla \\ Doutor em Administração pela Pontifícia Universidade Católica do Paraná, \\ Brasil. Professor da Universidade Estadual do Paraná, Brasil. \\ E-mail: juliocolla@gmail.com \\ Nelson Tenório \\ Doutor em Ciência da Computação pela Pontifícia Universidade Católica \\ do Rio Grande do Sul, Brasil. Professor do Centro Universitário de \\ Maringá, Brasil. \\ E-mail: nelson.tenorio@unicesumar.edu.br
}

\section{Resumo}

O conhecimento é um importante ativo para as organizações uma vez que é reconhecido pelo atual modelo econômico como essencial para a produtividade e a inovação. As organizações que gerenciam com excelência o conhecimento de seus recursos alcançam a melhoria da eficiência organizacional. Existem diversos modelos da Gestão do Conhecimento (GC) visando prover o desenvolvimento sustentável organizacional em um ambiente de competitividade e inovação. Entretanto, tais modelos têm dado pouca atenção à comunicação, que é essencial para que a informação ganhe fluência dentro da organização e gere conhecimento útil. Assim, o objetivo deste artigo é discutir os aspectos relevantes da comunicação nos principais modelos da GC no sentido de refletir o papel da comunicação nesses modelos e estimular novas pesquisas acerca do tema. Para tanto, são apresentados e discutidos os modelos consolidados pela literatura da GC por meio de pesquisa bibliográfica e exploratória, considerando aspectos como o processo explícito da comunicação nesses modelos, o grau do fator de pertinência e a importância da comunicação para esses modelos e, finalmente, as estratégias de comunicação que atendem os objetivos dos modelos. Os resultados alcançados mostraram que nenhum dos modelos analisados consideram explicitamente os aspectos relevantes da comunicação, e que isso é importante para que o conhecimento ganhe fluência e seja útil dentro da organização. Assim, não tratar de forma explícita os aspectos da comunicação dentro dos modelos da GC dificulta o compartilhamento e uso efetivo do conhecimento nesses modelos.

Palavras-chave: Comunicação. Modelos. Organizações. Gestão do Conhecimento. 


\title{
THE ROLE OF THE COMMUNICATION IN KNOWLEDGE MANAGEMENT: THE RELEVANT ASPECTS AND NEW RESEARCH MOTIVATIONS
}

\begin{abstract}
Knowledge is an essential asset to organizations once the current economic model recognizes it as necessary to improve productivity and innovation. The organizations that manage with excellence the knowledge of their resources achieves the improvement of the organizational efficiency. There are several models of Knowledge Management (KM) aimed at providing sustainable organizational development in an environment of competitiveness and innovation. However, such models have considered less attention to the communication, which is essential for information to gain fluency within the organization, generating useful knowledge. Thus, this article aims to discuss the relevant aspects of the communication in the primary KM models in order to reflect the role of the communication in those models and to stimulate new research on the topic. To do so, the models consolidated by KM literature through bibliographic and exploratory study. Thus, were considered aspects such as the explicit communication process in those models, the degree of the pertinence factor and the importance of communication for these models, and finally the communication strategies that meet the objectives of the models. The results showed that none of the analyzed models explicitly considers the relevant aspects of the communication and that this is important so that the knowledge gains fluency and is useful in the organization. Thus, not explicitly addressing the aspects of communication within the CG models hinders the sharing and effective use of knowledge in these models.
\end{abstract}

Keywords: Communication. Models. Organization. Knowledge Management.

\section{INTRODUÇÃO}

A origem dos estudos em GC nas organizações está pautada na pesquisa de Nonaka (1991), que cunha o conceito de knowledge-creating organization, ou 'organizações que criam conhecimento'. Segundo o autor, tais organizações são capazes de criar e disseminar novos conhecimentos, inserindo-os nos seus produtos, serviços e sistemas por meio de um processo que identifica, codifica e compartilha as informações a partir do reconhecimento dos conhecimentos tácito (i.e., difícil de representar e intrínseco ao indivíduo) e explícito, que é aquele que pode ser capturado e representado (NONAKA, 1991; NONAKA; VON KROGH; ICHIJO, 1997). Desde então, a GC passou a ser definida como uma atividade organizacional relacionada à busca, criação, transferência e uso do de conhecimento (NONAKA, 1991; DAVENPORT; DE LONG; BEERS, 1998), com vistas à sustentação e à promoção do desempenho global de uma organização (ANDRADE et al., 2011; CANONGIA et al., 2004).

Entretanto, o interesse recente pelo conceito de conhecimento - ao menos quando aplicado às organizações - tem sua origem na 'Economia do Conhecimento', de Peter Drucker (1994). O autor sugere que tanto a capacidade intelectual quanto o conhecimento representam o novo e mais valioso recurso econômico, superando os tradicionais fatores de produção (DRUCKER, 1994; FIALHO et al., 2006). Assim, a transição de qualquer nação para a economia do conhecimento implica em converter a tecnologia e o conhecimento nos motores do desenvolvimento. Tal transição envolve estratégias de competitividade com suporte em especializações avançadas, que capacitam os envolvidos a criarem vantagens competitivas. Essa nova economia considera o reconhecimento do capital humano como base da eficiência econômica e produtiva de um país (VELLOSO, 2005).

Nesse contexto, a GC assume papel de protagonismo. É ela que irá propor arranjos organizacionais para que o conhecimento seja criado, disseminado e utilizado pelas organizações (RIBEIRO, et al., 2017; SAITO; SANTOS, 2017). Porém, o conhecimento é um ativo intangível (STEFANO et al., 2014), e um dos pressupostos que norteia os modelos da GC é a

Perspectivas em Gestão \& Conhecimento, João Pessoa, v. 8, n. 2, p. 62-81, mai./ago. 2018. 
instituição de processos para sua codificação e compartilhamento, objetivando o aumento de competitividade e inovação (DALKIR, 2011; TAKEUCHI; NONAKA, 2008). Logo, determinar quais fatores promovem ou impedem o compartilhamento desse conhecimento dentro das organizações constitui uma importante questão (HOOF; RIDDER, 2004).

Dessa forma, na tentativa de transformar o conhecimento organizacional em um recurso, pesquisadores contemporâneos da área da GC criaram e testaram modelos de ciclos estruturados para gerenciar o conhecimento organizacional de forma eficaz e sistematizada. Esses modelos assumem o complexo papel de converter o conhecimento de tácito em explícito, descrevendo sistematicamente os processos para a identificação, criação, codificação, armazenamento, compartilhamento, aplicação e reutilização desse conhecimento nas organizações (DALKIR, 2011). Além disso, esses modelos elevam a capacidade de controle dos processos de tomada de decisão como estratégia organizacional (FIALHO et al., 2006).

Entretanto, os modelos da GC estão muito vinculados à noção de que o conhecimento deva ser um recurso manipulável, disponível, estocável e gerenciável. Assim, os aspectos subjetivos e completamente pueris das atividades sociais dentro das organizações são quase que totalmente negligenciadas por esses modelos. Um dos aspectos negligenciados é a comunicação organizacional, que ocorre por meio de processos comunicacionais e ciclos de informação, onde ambos estão presentes na evolução das estratégias empresariais e na própria evolução das organizações (CARDOSO, 2006).

Portanto, o objetivo deste artigo é discutir os aspectos relevantes da comunicação nos modelos da GC no sentido de refletir o papel da comunicação nesses modelos e estimular novas pesquisas acerca do tema. Para tanto, a metodologia utilizada foi a revisão bibliográfica dos modelos teóricos da GC consolidados na literatura e do processo de comunicação organizacional. Os resultados foram alcançados por meio de uma análise empírica de quatro fatores estabelecidos para nortear esta pesquisa, sendo eles: i) o processo de comunicação explicitado pelo modelo; ii) o grau de pertinência da comunicação no modelo (alto/médio/baixo); iii) a importância da comunicação para esses modelos; e iv) a estratégia de comunicação para cada modelo. Os resultados foram discutidos com as bases teóricas aqui apresentadas.

O presente artigo está organizado em seis seções. Após esta seção de introdução, a seção seguinte apresenta os modelos da GC mais consolidados da literatura, onde há uma descrição da estrutura e do funcionamento de cada modelo estudado. A seção 3 apresenta a importância e os aspectos da comunicação dentro das organizações. A seção 4 apresenta a metodologia utilizada desta pesquisa. A seção 5 apresenta tanto os resultados alcançados pela pesquisa quanto as discussões, quando são apresentadas a análise e os aspectos da comunicação nos modelos aqui estudados. Finalmente, são apresentadas as conclusões seguidas das referências bibliográficas.

\section{MODELOS DA GESTÃO DO CONHECIMENTO}

Dentro do princípio econômico, os fatores decisivos para a produção evoluíram ao longo do tempo (i.e., a terra e o capital), acompanhando a evolução tecnológica. $\mathrm{Na}$ atualidade, o fator de produção é cada vez mais o homem e o seu conhecimento (STEWART, 1998), proporcionando a vantagem competitiva para as organizações com base em experiência, julgamento, insight, contexto e informação 'adequada' (RIBEIRO, et al., 2017). Assim, o entendimento e significado se tornam pré-requisitos para tomada de medidas eficazes, criando valor e garantindo a sobrevivência e crescimento das organizações (DAL KIR, 2011). Além disso, as organizações passaram a ser intensivas em conhecimento buscando aprimorar continuamente seu ambiente para favorecer novos conhecimentos e ideias, agregando assim mais valor aos seus produtos e serviços (WILLERDING, 2016). Logo, a GC se

Perspectivas em Gestão \& Conhecimento, João Pessoa, v. 8, n. 2, p. 62-81, mai./ago. 2018. 
figura como o capital intelectual das organizações, com um papel fundamental na nova economia do conhecimento. Nesse contexto, surgem os modelos conceituais da GC que abrem novos caminhos para a estruturação sistêmica do conhecimento para que as organizações alcancem inovação e sustentabilidade.

\subsection{Modelo de Von Krogh e Roos}

O modelo da GC de von Krogh e Roos (1995) é embasado em dois tipos de epistemologia organizacional: a cognitiva e a conectiva. A epistemologia cognitiva enxerga o conhecimento organizacional como um sistema auto organizado. Segundo essa visão, os seres humanos são transparentes para as informações a partir do exterior, i.e., as pessoas identificam ou reconhecem as informações por meio de seus sentidos, usando essas informações para construir seus modelos mentais. Por outro lado, a epistemologia conectiva é mais holística, i.e., apresenta uma visão do todo e afirma que a aprendizagem ocorre a partir de vários componentes da rede interna de cada indivíduo e das conexões suas realizadas. Portanto, uma informação não é criada apenas a partir do ambiente, mas também gerada internamente. Além disso, não há um sistema organizado esperando pela informação, o sistema só é criado a partir das redes já existentes em cada indivíduo. Logo, a informação adquire seu próprio significado dependendo daquelas já existentes em cada indivíduo (DALKIR, 2011).

O modelo de von Krogh e Roos possui enfoque conectivo quando o conhecimento reside tanto nos indivíduos de uma organização quanto nas relações entre esses indivíduos. É a partir dessas relações que nasce a nova informação e, posteriormente, o conhecimento. 0 conhecimento é 'incorporado' quando, segundo os autores, "tudo o que se sabe é conhecido por alguém" (VON KROGH e ROOS, 1995, p. 50). O modelo salienta a importância da GC a partir das pessoas, e então a inter-relação entre o indivíduo e a organização na troca de conhecimentos, sendo importante a figura de um facilitador nesse contexto, pois exerce o papel de fomentar a relação e a comunicação dentro do ambiente organizacional. Assim, é imprescindível nesse modelo há a necessidade em se manter as ligações entre os objetos de conhecimento e àqueles que estão bem informados sobre eles, como autores, especialistas no assunto, e usuários experientes que aplicam o conhecimento com ou sem êxito (VON KROGH e ROOS, 1995).

Entretanto, o modelo de von Krogh e Roos apresenta a comunicação organizacional como uma das barreiras para o seu funcionamento ideal nas organizações (CRISTEA; CAPATINA, 2009). Isso porque, quando não existe uma linguagem comum para explicitar novos conhecimentos, a comunicação depende da criação de um 'terreno comum' (common ground) onde todos possam compreender, assimilar e discutir um conhecimento em comum (CLARK; BRENNAN, 1991). Portanto, nesse modelo, ao se considerar a inter-relação como gatilho para a construção e troca de novos conhecimentos, fica evidente o papel da comunicação como agente viabilizador desse processo, independentemente do meio ou forma utilizados. Assim, explicitar os aspectos de comunicação para esse modelo, bem como as suas diversas possibilidades, se faz essencial para que o conhecimento tenha fluência na organização.

\subsection{Modelo de Nonaka e Takeuchi}

No modelo conhecido como 'Modelo Espiral do Conhecimento', Nonaka e Takeuchi têm como base a epistemológica a distinção entre o conhecimento tácito e explícito. Assim, "a chave para a criação do conhecimento reside na mobilização e na conversão do conhecimento tácito" (TAKEUCHI; NONAKA, 2008, p. 54). Igualmente, os autores apresentam sua própria ontologia no que diz respeito aos níveis dos fatores atuantes na construção do conhecimento,

Perspectivas em Gestão \& Conhecimento, João Pessoa, v. 8, n. 2, p. 62-81, mai./ago. 2018. 
sendo eles individual, em grupo, organizacional e interorganizacional (TAKEUCHI; NONAKA, 2008 , p. 54). Portanto, no modelo proposto pelos autores, o conhecimento é criado a partir da 'espiral do conhecimento', que surge quando há a interação entre o conhecimento tácito e o conhecimento explícito. Esse novo conhecimento, que sempre se inicia a partir de uma pessoa, muitas vezes ocorre de forma inesperada e se concretiza como parte da rede do conhecimento da organização.

De acordo com Takeuchi e Nonaka (2008), existem quatro modos de conversão do conhecimento, conhecidos como socialização, quando o conhecimento se converte de tácito para tácito; externalização, quando o conhecimento é convertido de tácito para explícito; combinação, quando o conhecimento é convertido de explícito para explícito; e, finalmente, a internalização, nesse caso o conhecimento é convertido de explícito para tácito.

Na socialização, a pessoa vivencia o compartilhamento de experiências, criando assim um conhecimento tácito e inerente a ela, é nesse processo que uma informação, ou um dado, transforma-se em pensamentos. Na externalização, o conhecimento passa por um processo de codificação e de explicitação do conhecimento tácito da pessoa. Os autores sugerem que a forma mais eficaz de transformar conhecimento tácito em explícito é utilizar o uso sequencial da metáforas, analogias e modelos. Na combinação, os indivíduos trocam e combinam conhecimento através de documentos, reuniões, conversas telefônicas ou redes sociais. O uso das redes de comunicação como e-mails, chat, redes sociais, dentre outros, de forma eficiente e criativa contribui para esse modo de conversão do conhecimento. Na internalização, a pessoa 'aprende fazendo', i.e., a partir do conhecimento explícito encontrado em diferentes formas (e.g., documentos, manuais, base de dados, histórias, conversas, discussões e relatos), ela aplica na prática e internaliza essas informações, criando para si um novo conhecimento tácito (TAKEUCHI; NONAKA, 2008). A Figura 1 apresenta o Modelo da Espiral do Conhecimento de Nonaka e Takeuchi (1997).

Figura 1 - Modelo da Espiral do Conhecimento

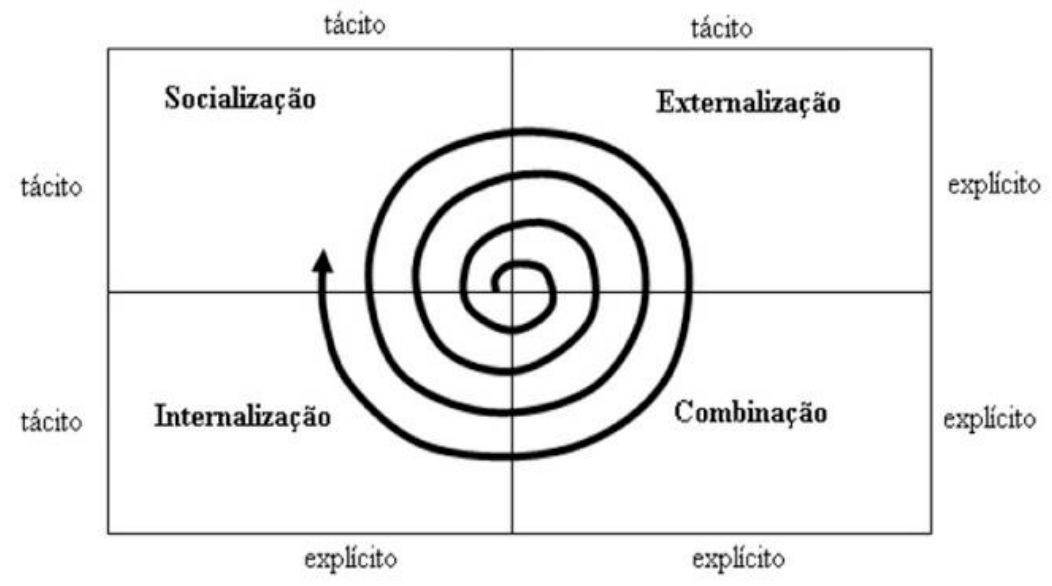

Fonte: Nonaka; Takeuchi (1997, p.80)

O Modelo Espiral do Conhecimento tem seu foco em descomplicar a compreensão e a aplicabilidade da transformação do conhecimento tácito em explícito. Por isso, Nonaka e Takeuchi (1997) sugerem formas de estimular as pessoas na produção do conhecimento organizacional, são elas:

- Intenção. A formulação da estratégia em um ambiente de negócios; a aspiração de uma organização, i.e., seus objetivos.;

- Autonomia. Condição em que os indivíduos agem de forma autônoma e estão envolvidos em equipes multifuncionais auto organizadas; 
- Flutuação e caos criativo. Condição que estimula a interação entre a organização e o ambiente externo e/ou cria flutuações e variáveis por meio de caos criativo;

- Redundância. Existência de informações que vão além dos requisitos operacionais imediato dos membros da organização; há a competitividade entre múltiplas equipes sobre o mesmo assunto e a rotação estratégica de pessoal;

- Requisito variedade. Diversidade interna para combinar com a variedade e complexidade do meio ambiente, e para fornecer a todos na organização o acesso mais rápido à variedade mais ampla de informações necessárias; a estrutura organizacional é flexível e interligada com redes de informações.

Observa-se que essas formas de estímulos são dependentes da comunicação. Portanto, embora esse seja um dos modelos mais expressivos da GC, ele não apresenta explicitamente os aspectos da comunicação, essenciais para se evitar distorções na informação e assim criar conhecimento útil que favoreça as tomadas de decisões.

\subsection{Modelo Choo}

O modelo da GC proposto por Choo (1998) tem como ênfase a criação do conhecimento a partir daquilo que faz sentido para a organização. Segundo os seus princípios epistemológicos, o conhecimento se caracteriza por se dar sentido ou compreender a informação a partir de seu contexto, possibilitando assim a criação de conhecimento e a tomada de decisão. $O$ modelo tem o enfoque em como os elementos da informação são selecionados e, posteriormente, incorporados às ações da organização. Para o autor, o êxito da GC faz surgir as 'organizações inteligentes', i.e., àquelas que são capazes de perceber e processar informações, criar conhecimento a partir da informação processada e utilizar o conhecimento para tomada de decisão (CHOO, 1998). O modelo Choo, em sua versão mais recente, Choo (2006), apresenta uma estruturação para os fluxos internos da organização que busca aproveitar a experiência e o conhecimento de seus colaboradores, criando significados comuns e explorando novos conhecimentos (SANTOS; TRZECIAK; RADOS, 2017). Logo, o modelo enfatiza três pontos, são eles:

- Produção de sentido: que significa dar sentido ou compreender a informação a partir de seu entorno ou do contexto exterior;

- Criação do conhecimento: é a transformação do conhecimento individual em conhecimento compartilhado por meio do diálogo e compartilhamento;

- Tomada de decisão: é a avaliação e a análise das informações e conhecimentos obtidos que permitem o julgamento das possibilidades e posterior tomada de decisão.

Um ponto forte do modelo Choo (2006) é a tomada de decisão, que está situada em modelos racionais utilizados para identificar e avaliar as alternativas, o processamento da informação e o conhecimento coletado até o momento (DALKIR, 2011). Assim, a tomada de decisão apresenta uma visão holística do processo da GC e se estende para dentro da organização. Desse modo, um dos pilares desse modelo é a construção do conhecimento, que ocorre a partir da conversão do conhecimento individual em coletivo ou organizacional. Para o modelo, o diálogo é uma forte ferramenta de compartilhamento do conhecimento em que a boa comunicação exerce um papel fundamental nesse processo. Entretanto, os processos e as estratégias de comunicação não são explicitados no modelo, o que pode gerar conhecimento que não faça sentido para a organização. Portanto, identificar os aspectos de comunicação e estabelecer as suas estratégias de melhoria, aumentam a chance de tomadas de decisão mais acertadas.

Perspectivas em Gestão \& Conhecimento, João Pessoa, v. 8, n. 2, p. 62-81, mai./ago. 2018. 


\subsection{O Modelo Wiig}

O princípio do modelo da GC proposto por Wiig (1993) é que o conhecimento só é útil e valioso se estiver organizado de acordo com o seu objetivo. O modelo baseia-se na exploração e adequação do conhecimento considerando as seguintes dimensões:

- Plenitude. Todo o conhecimento importante deve ficar disponível; suas fontes podem diversas, inclusive de conhecimento tácito e conhecimento explícito. Os indivíduos devem saber que o conhecimento está disponível e onde buscá-lo;

- Conectividade. Poucos objetos de conhecimento são totalmente desconectados de outros, quanto mais ligado a base de conhecimento (i.e., maior o número de interligações da rede semântica), mais coerente é ao conteúdo e maior é o seu valor;

- Congruência. Todos os fatos, conceitos, perspectivas, valores, julgamentos e vínculos associativos e relacionais entre os objetos de conhecimento são consistentes. Os conceitos e definições também devem ser consistentes e a base de conhecimentos como um todo precisa ser alinhada constantemente para manter a congruência;

- Perspectiva/Propósito. Refere-se ao fenômeno pelo qual 'sabe-se algo', muitas vezes a partir de um ponto vista particular ou para um fim específico.

- O modelo, então, propõe três formas de conhecimento: público, compartilhado e pessoal. Além disso, o autor tipifica o conhecimento em factual, conceitual, perspectiva e metodológico. Juntas, as três formas e os quatro tipos de conhecimento, combinam-se para produzir uma matriz da GC que constitui a base do modelo, conforme o Quadro 1.

Quadro 1 - Formas e tipos de conhecimentos

\begin{tabular}{|c|l|l|l|l|}
\hline \multirow{2}{*}{$\begin{array}{c}\text { Formas de } \\
\text { Conhecimento }\end{array}$} & \multicolumn{4}{|c|}{ Tipos de Conhecimento } \\
\cline { 2 - 5 } & \multicolumn{1}{|c|}{ Factual } & \multicolumn{1}{|c|}{ Conceitual } & \multicolumn{1}{c|}{ Perspectivas } & \multicolumn{1}{c|}{ Metodológico } \\
\hline \multirow{2}{*}{ Público } & $\begin{array}{l}\text { Medidas e } \\
\text { Leituras. }\end{array}$ & $\begin{array}{l}\text { Estabilidade e } \\
\text { Balanço. }\end{array}$ & $\begin{array}{l}\text { Oferta maior que } \\
\text { demanda. Queda } \\
\text { de preço. }\end{array}$ & $\begin{array}{l}\text { Buscar por } \\
\text { temperatura, fora } \\
\text { das normas. }\end{array}$ \\
\hline \multirow{2}{*}{ Compartilhado } & $\begin{array}{l}\text { Prognóstico e } \\
\text { análise. }\end{array}$ & $\begin{array}{l}\text { Mercado } \\
\text { aquecido. }\end{array}$ & $\begin{array}{l}\text { Um pouco de água } \\
\text { na mistura está } \\
\text { bom. }\end{array}$ & $\begin{array}{l}\text { Busca falhas no } \\
\text { passado. }\end{array}$ \\
\hline \multirow{2}{*}{ Pessoal } & $\begin{array}{l}\text { Cor e textura } \\
\text { correlatas. }\end{array}$ & $\begin{array}{l}\text { A organização } \\
\text { tem uma boa } \\
\text { trajetória. }\end{array}$ & $\begin{array}{l}\text { Pressentimento de } \\
\text { que a análise está } \\
\text { errada. }\end{array}$ & $\begin{array}{l}\text { Qual é a tendência } \\
\text { atual? }\end{array}$ \\
\hline
\end{tabular}

Fonte: adaptado de Dalkir (2011)

O modelo Wiig (1993) permite que a GC seja praticada com mais refinamento que os outros modelos. Isso porque ele se baseia em tipos de conhecimento e vai além da simples dicotomia tácito/explícito (DALKIR, 2011). Além disso, o modelo reforça o uso do conhecimento e descreve o seu conteúdo, sua localização, sua captura, distribuição e nova localização. Assim, percebe-se que para um modelo com tantas especificidades, (i.e, descrição, a localização, a captura e a distribuição do conhecimento), a boa comunicação é essencial uma vez que o modelo estabelece diferentes níveis de conhecimento, e.g., novato, iniciante, competente, especialista e mestre. Portanto, identificar e analisar os aspectos da comunicação nesse modelo tornam-se primordiais, uma vez que favorecem estratégias para a sistematização do conhecimento, tornando-o útil e valioso para toda a organização.

Perspectivas em Gestão \& Conhecimento, João Pessoa, v. 8, n. 2, p. 62-81, mai./ago. 2018. 


\subsection{Modelo I-Space de Boisot}

O I-Space é um modelo da GC proposto por Boisot (1998) que se baseia no conceito da 'boa informação', i.e., uma informação compreendida a partir de um determinado contexto. No modelo, há também a distinção entre informação e dado, quando o autor sugere que a informação é o que um observador extrai a partir de dados observados e conhecidos. Assim, o I-Space sugere que uma informação eficaz depende do conteúdo compartilhado entre os seus emissores e receptores e, ainda, ambos são dependentes da codificação ou linguagem utilizada. Dessa forma, a informação só é importante se possuir um contexto no qual possa ser interpretada, criando um 'terreno comum' e possibilitando um conhecimento efetivo (CLARK; BRENNAN, 1991). No entanto, um contexto pode ainda não ser suficiente para garantir o entendimento da informação, por exemplo, haverá situações em que o conhecimento tácito será perdido quando codificado para explícito. Essa situação desencadeia a necessidade de um compartilhamento face-a-face. Portanto, o modelo pressupõe que um conteúdo bem codificado deve apresentar um nível alto de contextualização para facilitar a compreensão da informação.

O I-Space está estruturado sobre dois pilares. O primeiro é que quanto mais facilmente um dado é estruturado, mais passível de difusão ele se torna. O segundo é que havendo menos dados estruturados, é necessário um contexto compartilhado para sua difusão, tornando-o mais passível de difusão. Assim, após serem compreendidos por meio dos processos de codificação e abstração, os dados são estruturados facilitando a fluidez e a amplitude do conhecimento. No I-Space, os ativos do conhecimento situam-se dentro de um espaço tridimensional denominado 'espaço de informação'. Tal espaço é definido por três dimensões, sendo elas a dimensão de codificação, que está associada à categorização e à classificação dos dados; a dimensão de abstração, que está associada à criação do conhecimento por meio da análise e compreensão dos dados; e a dimensão de difusão, que possibilita o acesso e à transferência de informação.

O modelo também incorpora uma fundamentação teórica do ciclo de aprendizagem social para unir o conteúdo, a informação e a GC de uma forma eficaz, propondo assim um fluxo dinâmico de conhecimento por meio de seis fases, sendo elas:

- Scanning. Fase em que é possível identificar ameaças e oportunidades. Ela é muito dependente da codificação dos dados e pode ser rápida quando os dados são bem codificados e abstraídos ou ser lenta e aleatória quando os dados não são bem codificados;

- Solução de problemas. Onde ocorre o processo de estruturação e de tornar os insights coerentes para a codificação. Assim, os insights adquirem uma forma mais definitiva e muito da incerteza associada a eles é eliminada;

- Abstração. Generaliza os insights recém-codificados em outras situações de aplicação, reduzindo os seus detalhes e criando conceitos acerca deles. Em geral, ocorre em conjunto com a fase de solução de problemas;

- Disseminação. Possibilita o compartilhamento dos insights criados. 0 compartilhamento de dados bem codificados e abstraídos com uma ampla população, é menos problemático do que quando os dados muito especializados e sem codificação;

- Assimilação. Aplica os novos insights codificados em situações diferentes do tipo 'aprender fazendo' ou 'aprender usando';

- Impacto. Incorpora os conhecimentos abstraídos de práticas concretas. Essa incorporação pode ocorrer em artefatos, regras organizacionais, técnicas ou em padrões comportamentais. $\mathrm{O}$ impacto, normalmente, ocorre após a assimilação.

Perspectivas em Gestão \& Conhecimento, João Pessoa, v. 8, n. 2, p. 62-81, mai./ago. 2018. 
Embora esse modelo seja menos conhecido e testado, ele possui um forte potencial para mapear e gerenciar os ativos de conhecimento de uma organização com base no ciclo de aprendizagem social, que não é explicitamente discutido pelos outros modelos da GC. Sendo assim, a comunicação faz-se essencial nesse modelo, uma vez que há diversos tipos de interação para a promoção da aprendizagem social. Portanto, explicitar os aspectos de comunicação desse modelo é uma forma de se evitar que os dados coletados gerem conhecimentos superficiais e distantes da realidade.

\subsection{Modelo Sistema Adaptativo Complexo Inteligente (ICAS)}

O ICAS é um modelo da GC voltado para organizações que estabelecem diferentes laços de relação simbiótica com empresas cooperativas, alianças virtuais e ambiente externo (BENNET; BENNET, 2003). Essas organizações se caracterizam por realizar constantemente a identificação e a seleção de ameaças e oportunidades do mercado em que atuam. Os processos-chaves no modelo são o entendimento, a criação de novas ideias, a resolução de problema, a tomada de decisões e as ações para alcançar os objetivos desejados pela organização. Assim, o modelo sugere oito características emergentes para que as organizações possam competir e ter sucesso no mercado.

A primeira característica é a 'inteligência organizacional', que é considerada uma fonte de competitividade em que o resultado do aproveitamento dos pontos fortes das pessoas é direcionado para alavancar o conhecimento e manter a unidade do propósito. Trabalhando a inteligência emocional a organização viabiliza a inovação, a aprendizagem, a adaptação e as tomadas de decisões rápidas em situações imprevistas. A segunda característica é a 'unidade de propósito compartilhado' que, além de fornecer uma linha contínua de foco e atenção, faz a união das partes relevantes da organização quando e onde elas são necessárias. A terceira característica é a 'seleção', que é dada por um processo que realiza a filtragem da entrada de informações do ambiente externo. A quarta característica é a 'complexidade ótima', que consiste em reduzir a complexidade interna da organização, bem como reduzir os impactos da complexidade externa em seu ambiente. A quinta característica é conhecida como 'fronteiras permeáveis', que são formas de viabilizar a troca de conhecimentos e a construção de novas ideias. A sexta característica é a 'centralização do conhecimento', que consiste na agregação de informações relevantes à organização. A sétima característica é o 'fluxo', que garante a centralização do conhecimento e facilita as conexões e a continuidade necessária para que se mantenha a unidade e a coerência da inteligência organizacional. A oitava e última característica é a 'multidimensionalidade', que representa a habilidade organizacional de possibilitar que seus trabalhadores desenvolvam suas competências, perspectivas e suas capacidades cognitivas para serem aplicadas na tomada de decisão e na resolução de problemas.

No ICAS, a produção do conhecimento, tanto interno quanto externo, ocorre natural e continuamente por meio das interações entre os agentes envolvidos. Há também uma forte valorização do indivíduo como fonte produtora do conhecimento, bem como, a estratégia de gerir o processo objetivando o sucesso da organização. Para alavancar os ativos do conhecimento, o modelo sugere $o$ uso de redes múltiplas a fim de que haja 0 'transbordamento' de informações, que é uma forma de converter o conhecimento tácito em explícito, e.g., as comunidades de prática (CoP) e os repositórios de conhecimento. Assim, o conhecimento dá ao trabalhador a capacidade de tomada de decisões eficientes, possibilitando um processo de inovação contínuo para a organização. Logo, um dos pontos chave do modelo é o entendimento das informações para que essas gerem conhecimento. Entretanto, isso depende significativamente da qualidade da comunicação empregada, no caso do ICAS, a comunicação face a face. Portanto, entender os aspectos de comunicação desse

Perspectivas em Gestão \& Conhecimento, João Pessoa, v. 8, n. 2, p. 62-81, mai./ago. 2018. 
modelo é importante, uma vez que ele tem como foco a produção do conhecimento por intermédio da interação entre os agentes envolvidos.

\section{COMUNICAÇÃO ORGANIZACIONAL}

A Comunicação Organizacional começa a se estabelecer como um campo de estudos dentro da gestão desde, ao menos, meados do século XX (CHENEY, 2007). Seus primeiros passos possuíam nítido contorno gerencial. Primeiro, como respostas às necessidades organizacionais de entender os fluxos de informação, os canais de comunicação e os meios disponíveis. Segundo, pelo fato de que o acesso mais comum ao campo se dava por meio de gestores de cúpula interessados, naturalmente, em resolver problemas organizacionais relacionados à produtividade e a eficiência (CHENEY, 2007). A partir da década de 1980, entretanto, o campo passa a incorporar um arco maior de temas, incluindo estudos de gênero (SCHOENEBORN, 2013; CHENEY, 2007), raciais (ASHCRAFT; ALLEN, 2003), de cultura (AHMETI, 2014), liderança e poder (NORLYK, 2009), entre outros; bem como perspectivas teóricas de campos que avançavam concomitantemente em temas semelhantes como a sociologia das organizações e os estudos organizacionais (MUMBY, 2012). Romper com o isolacionismo enriqueceu o campo e abriu possibilidades para novas intersecções.

Nas organizações, a comunicação desempenha papel fundamental atuando como agente viabilizador de qualquer processo (ALMEIDA, 2003). Como atividade socialorganizacional, implica "[...] na interação e produção de mensagens com significados, através de diferentes canais e meios de forma a impactar/influenciar, de alguma maneira, no comportamento de outros, na organização e no desenvolvimento dos sistemas sociais" (PEPULIM; FIALHO; SOUZA, 2013, p. 40). Nesse sentido, a comunicação cumpre a função de coordenar conhecimentos dispersos entre os diversos indivíduos e grupos organizacionais, e pode vir a possibilitar o uso intensivo de conhecimento pela organização (GARICANO; WU, 2012), em seus ambientes internos e externos.

A comunicação interna é uma necessidade, uma vontade e uma crença da organização (ALMEIDA, 2003). É uma necessidade porque é vital na coordenação das atividades e dos processos, além de influenciar o clima interno. É uma crença porque acredita-se que a comunicação interna pode levar à solução de problemas. Por fim, é uma vontade porque é necessário pensar, controlar e geri-la por meio das opções estratégicas (ALMEIDA, 2003). A comunicação externa, por outro lado, cumpre a função de criar, manter ou aprimorar a imagem organizacional (PENTEADO, 2012). Em ambos os ambientes organizacionais, a comunicação é a variável que molda a relação entre o conhecimento individual e o organizacional, cujas consequências podem ser sentidas nos processos e estruturas organizacionais e nas tomadas de decisão estratégicas (GARICANO; WU, 2012).

Dessa forma, a comunicação possui impacto direto na performance organizacional e no alcance dos objetivos propostos (MALMELIN, 2007). Em particular, a comunicação codificada (explícita) permite a divisão do trabalho e a especialização baseada em conhecimento; e a comunicação não codificada (baseada em conhecimento tácito), alimenta tomadas de decisão e a navegação estratégica pelo ambiente externo (GARICANO; WU, 2012). Assim, enxergar a comunicação como uma variável independente do conhecimento, em uma relação recursiva de influências, pode ser a chave para a busca organizacional por comportamentos inovadores, criativos e dinâmicos do ponto de vista estratégico. Além disso, ela atua como disseminadora dos objetivos e dos valores culturais da empresa para públicos internos e externos (CARDOSO, 2006).

Em todos os ambientes, inclusive nos organizacionais, a comunicação não ocorre apenas pelo meio oral. Ela ocorre também por diversos outros meios, com ou sem intervenções tecnológicas, tais como documentos, quadros de avisos, recados, dentre outros.

Perspectivas em Gestão \& Conhecimento, João Pessoa, v. 8, n. 2, p. 62-81, mai./ago. 2018. 
Além disso, há inúmeras formas de comunicação não verbal, constituídas por expressões faciais e tom de voz, que por inúmeras vezes complementam a mensagem e influenciam no seu entendimento, podendo evitar distorções na interpretação da mensagem. Para Gomes (2000, p. 167) "[...] o paradigma dominante da comunicação fá-la consistir no movimento de uma substância (mensagem) que, deslocando-se de um ponto para o outro, pode encontrar barreiras ou filtros redutores da transmissão eficaz".

Além disso, é imprescindível a compreensão dos elementos e obstáculos que possam comprometer ou perturbar a comunicação, de modo que se possa melhorar o ambiente organizacional (REGO, 2016). O ruído, por exemplo, é uma interferência indesejável que pode ocorrer em qualquer processo de comunicação e pode resultar em perdas ou desvios na mensagem transmitida. Assim o ruído na comunicação humana é um conjunto de barreiras, obstáculos, acréscimos, erros e distorções que prejudicam a compreensão da mensagem em um fluxo bilateral entre o emissor e o receptor (CARVALHO; PAULO; SERAFIM 2014).

A existência de ruído na comunicação compromete a compreensão da mensagem proposta e produz incertezas em seu conteúdo. Na maioria das vezes, os ruídos surgem em razão do emissor não transmitir ao destinatário sua mensagem ou informação com eficácia (PMI, 2017). Ao aprofundar os estudos sobre as barreiras comunicacionais, Ramal (2010) apresenta as especificidades inerentes a esse conceito, expondo três classes de ruídos comumente presentes na comunicação. $O$ primeiro deles é o semiótico, que ocorre quando o contexto não é compartilhado pelo emissor e receptor. Assim, o ruído semiótico é caracterizado pela incompreensão por parte do receptor de uma mensagem ou questão apresentada por um emissor. O segundo deles é o ruído físico, que afeta a mensagem dentro de um canal. Podem ocorrer ruídos físicos nas trocas de mensagens na utilização de recursos ou ferramentas assíncronas. Por fim, o ruído ideológico, produzido quando o subcódigo do emissor não é assimilado pelo subcódigo do receptor. Os ruídos ideológicos são a principal causa de falha na comunicação entre emissor/receptor. Na maioria das vezes esse tipo de ruído ocorre devido ao pouco conhecimento do receptor em relação aos temas ou conteúdos abordados. Dessa forma, os obstáculos que interferem diretamente na comunicação precisam ser analisados e repensados a fim de que possam ser revertidos, proporcionando um ambiente adequado à implantação de qualquer sistema de gestão, inclusive a GC, dentro de uma organização tendo como base uma comunicação de qualidade.

Para evitar ruídos de comunicação e melhorar a fluência da informação nas organizações, diferentes estratégias podem ser utilizadas. O PMBOK@ apresenta três métodos de comunicação para evitar ruídos de comunicação em projetos (PMI, 2017), sendo elas:

- Comunicação interativa. Ocorre entre duas ou mais partes quando há troca multidirecional de informações. Exemplos de estratégias de comunicação interativa são reuniões, ligações telefônicas, uso de comunicadores que permitam mensagens instantâneas, vídeo conferências etc.;

- Comunicação ativa. A informação é enviada destinada especificamente para os usuários envolvidos. Exemplos de estratégias de comunicação ativa são cartas, memorandos, relatórios, e-mails, fax, mensagens de voz, blogs etc.;

- Comunicação passiva. Usada para um grande volume de informação ou quando há um grande público. Exemplos de estratégias de comunicação passiva são intranet, elearning, base de dados de lições aprendidas, repositórios de conhecimento etc.

O conceito de facilitadores do modelo conectivo de von Krogh e Roos (1995), a ideia de produção de sentido do modelo de Choo (1998), a dimensão perspectiva/propósito de Wiig (1993), e o contexto da "boa informação" de Boisot (1998) são atravessados por formas diversas de comunicação para além da forma mais elementar da comunicação oral, ainda que não tenham sido sistematizados pelos respectivos autores. Além disso, todos os elementos

Perspectivas em Gestão \& Conhecimento, João Pessoa, v. 8, n. 2, p. 62-81, mai./ago. 2018. 
destacados desses modelos de GC são atravessados pelos obstáculos comunicacionais previstos por Rego (2016) e Ramal (2010). A ciência da existência dos diversos tipos de ruídos semióticos, físicos e ideológicos que impedem ou interrompem o fluxo de informações e ideias entre emissores e receptores (sujeitos organizacionais) pode provocar avanço substancial nos modelos de GC.

Nesse sentido, a comunicação exerce papel de facilitador estratégico dentro dos modelos. Por isso, há a necessidade de se tentar garantir que essa comunicação não possua ruídos, sob risco de haver comprometimento do resultado esperado. Como observado nos modelos da GC apresentados, o compartilhamento apresenta condição sine qua non em todos eles e, basicamente, qualquer tipo de compartilhamento dar-se-á por meio de algum tipo de comunicação, i.e., face a face ou utilizando-se de ferramentas de comunicação como e-mails, mensagens instantâneas, relatórios, memorando, chat, dentre outros. Assim, a comunicação no contexto da GC é um elemento crucial no desenvolvimento das atividades organizacionais (PEPULIM; FIALHO; SOUZA, 2013) uma vez que está implícita a todas elas e viabiliza, além da aprendizagem e da disseminação da cultura organizacional, a criação e o compartilhamento do conhecimento. Embora exista crença nos modelos da GC como intermediadores do sucesso organizacional, pouca atenção é dada à comunicação. Nesse sentido, os referenciais teóricos e metodológicos tradicionais da GC, bem como de todo o universo ligado às estratégias organizacionais, podem se beneficiar da inclusão da comunicação e dos processos comunicacionais em suas análises. Portanto, entender e explicitar os aspectos da comunicação de dentro dos modelos da GC é uma importante contribuição para essa área.

\section{METODOLOGIA}

Para se alcançar o objetivo deste artigo, realizou-se uma pesquisa exploratória bibliográfica durante o mês de abril de 2017, quando foram consultados livros, dissertações, teses e periódicos científicos relacionados ao contexto da GC, da comunicação e do papel da comunicação para as organizações. Assim, buscaram-se trabalhos em bases de dados de pesquisas na internet como: Periódicos da CAPES, Scielo, Emerald Insight, Google Scholar e Instituto Brasileiro de Informação em Ciência e Tecnologia (Ibict). Foram utilizadas as palavraschave em Língua Portuguesa "modelos da gestão do conhecimento" e "comunicação explícita" ou "estratégias de comunicação" e "aspectos da comunicação". Igualmente, foram utilizadas as palavras em Língua Inglesa "knowledge management models" e "explicit communication" ou "communication strategy" e "communication aspects". Dessa forma, foram encontrados 52 artigos científicos acerca do tema e selecionados 30 deles que tiveram aderência com o objetivo deste trabalho. Além disso, foram considerados livros seminais acerca do assunto. Com base na leitura da bibliografia selecionada, foram estabelecidos os seguintes fatores norteadores para análise dos modelos da GC:

i. Comunicação explicitada pelo modelo. Visa identificar se o modelo da GC trata explicitamente os aspectos da comunicação e, ainda, propõe processos para a sua fluência dentro da organização;

ii. Fator de pertinência. São os fatores de pertinência dos aspectos da comunicação para o modelo, sendo eles alto, médio e baixo. $O$ fator alto indica que o modelo da GC analisado é altamente dependente da comunicação, considerando-a primordial. Quando médio, o fator indica que o modelo da GC analisado não depende tanto dos aspectos da comunicação, mas também eles não são menos importantes. O fator baixo indica que o modelo não se preocupa com os aspectos da comunicação;

Perspectivas em Gestão \& Conhecimento, João Pessoa, v. 8, n. 2, p. 62-81, mai./ago. 2018. 
iii. Estratégias de comunicação. Apresenta a forma de como a comunicação pode ser implantada para auxiliar os modelos nos aspectos e na fluência da informação e do conhecimento dentro das organizações; e

iv. Importância da comunicação. Com base nos modelos da GC legitimado na literatura, apresenta-se uma análise sobre como o aspecto explícito da comunicação em um modelo pode contribuir para aprimorar a GC na organização.

Os dados coletados a partir das leituras do material selecionado, foram devidamente organizados em uma tabela onde era informado o nome do modelo da GC, seu objetivo e a forma como a comunicação contribuía para alcançar o seu objetivo. Além disso, foi colocada uma coluna que identificava se o modelo oferecia um processo explícito de comunicação. A partir disso, foram realizadas as análises desses modelos da GC e dos aspectos da comunicação com base em insights empíricos dos pesquisadores, devidamente embasados na teoria e norteados pelos nos fatores aqui estabelecidos, o que possibilitou a discussão dos resultados.

\section{RESULTADOS E DISCUSSÃO}

A comunicação possui um papel fundamental nas organizações, permitindo a criação e a manutenção tanto do seu conhecimento quanto do conhecimento de seus indivíduos. Contudo, por meio deste artigo, observou-se que nenhum dos modelos da GC estudados apresentam ou debatem explicitamente os aspectos da comunicação. Observa-se assim, que a comunicação é implícita em todos esses modelos. Investigando o modelo de von Krogh e Roos, nota-se que são propostas duas formas de aprendizado: o individual e o organizacional. Assim, enquanto o aprendizado individual ocorre, ele está alicerçado nas relações e comunicações a partir do processamento dos dados de uma informação recebida. Inversamente, o aprendizado organizacional ocorre com base nas redes que se auto organizam e são compostas por relações dirigidas pela comunicação (VON KROGH; ROOS, 1995). Entretanto, percebe-se que o modelo não descreve de forma explícita como deve ocorrer a comunicação entre os indivíduos para que o conhecimento ganhe fluência na organização. Portanto, considera-se como baixo o fator de pertinência da comunicação para esse modelo, tendo em vista que ele não trata como a comunicação deve ocorrer ao longo dos seus processos. Assim, o processo de comunicação do modelo pode ser alinhado com estratégias que mantivessem as ligações entre os objetos de conhecimento e os indivíduos que estão bem informados sobre eles (VON KROGH; ROOS, 1995). Logo, as estratégias de comunicação adotadas deveriam ser direcionadas no sentido do compartilhamento do conhecimento por meio da criação de canais de comunicação ativa (e.g., WhatsApp) para o envio de mensagens individuais. Essa estratégia possibilita o compartilhamento do conhecimento por meio de uma linguagem informal escrita ou verbal e, ainda, o envio de artefatos multimídia como fotos e vídeos, evitando assim ruídos ideológicos e distorções no aprendizado individual e organizacional.

No modelo Espiral do Conhecimento de Nonaka e Takeuchi (1995), todas as conversões e/ou codificações possíveis do conhecimento tácito e explícito passam pela comunicação escrita, falada ou desenhada. Trabalhar para que essa comunicação seja eficiente, torna-se fundamental para o sucesso da espiral proposta pelos autores. Assim sendo, explicitar o os aspectos da comunicação na espiral proposta, contribui consideravelmente para a construção de um novo conhecimento. No que tange ao fator pertinência analisado, observa-se como baixo, uma vez que não há indicação de como tratar a comunicação na espiral que o modelo apresenta. Referente a estratégia de comunicação, essa pode explorar a conversão do conhecimento tácito e explícito em todos os sentidos. Assim sendo, a criação de canais de comunicação interativos, como grupos de Facebook ou de WhatsApp, facilitam a

Perspectivas em Gestão \& Conhecimento, João Pessoa, v. 8, n. 2, p. 62-81, mai./ago. 2018. 
comunicação por meio de uma linguagem informal escrita com envios de artefatos multimídia como fotos e vídeos, movimentando o compartilhamento do conhecimento e estimulando a criação de novos conhecimentos, atendendo ao objetivo principal do modelo.

De acordo com o modelo da GC de Choo (2006), o conhecimento é criado pelo contato entre os indivíduos que pode se dar por meio do diálogo, do discurso, da partilha e do storytelling. Segundo o autor, os meios de contato entre os indivíduos só ocorrem quando há algum tipo de comunicação envolvido ou quando há o suporte por alguma ferramenta comunicacional. Porém, o modelo não mostra explicitamente os aspectos da comunicação. Isso demonstra a necessidade de um meio explícito de comunicação. Portanto, o fator pertinência do modelo é de nível médio, dado que para dar sentido às informações, pressupõe-se que seja necessária a compreensão dessas previamente e sem a 'contaminação' por ruídos na comunicação. Entretanto, evitar esse ruído só é possível se a comunicação empregada apresentar qualidade satisfatória para ambos, emissores e receptores da mensagem. Por se tratar de um modelo voltado à tomada de decisão e com uma visão holística dos processos da GC (e.g., quando a transformação do conhecimento individual deve ser compartilhada para toda a organização), entende-se que a estratégia de comunicação adotada deva ser passiva (i.e., quando se trata de um grande volume de informações ou voltada para um grande público) com o uso de uma linguagem formal tanto verbal quanto escrita. Assim, o objetivo do modelo pode ser alcançado, uma vez que tal estratégia evita que o conhecimento seja criado de forma a comprometer as decisões tomadas.

Segundo o modelo proposto por Wiig (1993), o conhecimento só é útil e valioso se estiver organizado, devendo ser organizado de acordo com seu objetivo e privilegiando uma internalização direcionada para diferentes níveis de internalização que o modelo estabelece, como nível novato, principiante, competente, especialista e mestre (DALKIR, 2011). Para gerar o conhecimento útil, a informação deve ser devidamente codificada para cada um desses níveis, sendo necessário a formação de um 'terreno comum' entre os indivíduos (CLARK; BRENNAN, 1991). Isso possibilita a internalização desse conhecimento para indivíduos de mesmo nível, por meio do compartilhamento apoiado por algum tipo de linguagem comum. Logo, o modelo Wiig (1993) baseia-se na exploração e adequação do conhecimento organizacional por meio de uma abordagem mais refinada da GC, que reforça o seu uso e descreve o seu conteúdo, como por exemplo, a localização, a captura, a distribuição e, então, a nova localização desse conhecimento. Assim, observa-se que o fator de pertinência da comunicação para esse modelo é de nível médio, pois ele é o resultado do estreitamento entre a existência ou criação do conhecimento e a sua codificação, i.e., descrição objetiva do contexto desse conhecimento dentro de um terreno comum para ser compartilhado. Entretanto, o modelo Wiig (1993) não trata os aspectos de comunicação de forma explícita, o que pode desencadear distorções nas informações que moldam o conhecimento a ser internalizado pelos indivíduos uma vez que o processo de comunicação passa a ser subjetivo. Deixar a comunicação explícita nesse modelo, pode aprimorar a descrição, localização, captura, distribuição e nova localização do conhecimento, essenciais para o compartilhamento e internalização desse conhecimento pelos indivíduos. Com relação às estratégias de comunicação que atendam as caraterísticas desse modelo, essa deve oferecer uma comunicação interativa e ativa com uma linguagem formal tanto escrita quanto verbal, gerando um conhecimento útil e direcionado aos indivíduos.

Ao analisar o modelo I-Space de Boisot (1998), identifica-se quão importante é o papel desempenhado pela comunicação. O modelo está centralizado na ideia da 'boa informação', que depende essencialmente da contextualização clara para a codificação das informações. Por isso, o fator de pertinência da comunicação do I-Space foi considerado alto, uma vez que o modelo sinaliza a importância do compartilhamento de conhecimento face a face como forma de garantir uma comunicação eficaz e a internalização do conhecimento adequada. Como esse

Perspectivas em Gestão \& Conhecimento, João Pessoa, v. 8, n. 2, p. 62-81, mai./ago. 2018. 
é um modelo que também não apresenta de forma explícita os aspectos da comunicação, a contextualização da informação pode perder riqueza em detalhes e objetividade. Isso é suficiente para propagar ruídos que comprometam a codificação dos dados de forma que essa informação se torne superficial e distante da realidade. Em relação à estratégia de comunicação, essa deve ser interativa e ativa com o uso de uma linguagem formal tanto escrita quanto verbal, permitindo assim a realização de uma comunicação eficiente e que contribua para uma codificação de dados de forma excelente, que nesse caso é a codificação mais próxima possível da realidade.

Para o modelo ICAS o entendimento da informação, para que então ela se torne conhecimento, é o pré-requisito para tomada de decisões eficazes (BENNET; BENNET, 2003). Esse entendimento se dá a partir das informações codificadas e compartilhadas com certa qualidade. Entretanto, como os demais modelos, o ICAS não deixa claro quais os aspectos da comunicação devem ser considerados para garantir que o entendimento da informação gere conhecimento. Entretanto, analisando o fator de pertinência da comunicação para modelo, esse foi considerado médio, pois embora não haja um aprofundamento da questão, há uma preocupação em filtrar as informações adequadas antes de capturá-las. Isso por si só contribui para evitar informações excessivas gerem mais ruídos, prejudicando a qualidade da informação e, por consequência, do conhecimento adquirido. Como estratégia de comunicação pode-se adotar a comunicação passiva (e.g., usada para grandes volumes de informações) e interativa (e.g., troca de informações troca multidirecional), com o uso de linguagem formal verbal. Assim, a comunicação do modelo deve ocorrer de modo que a mesma ideia transmitida por um ou mais indivíduo, seja aquela compreendida por outros indivíduos. Evitando, desse modo, distorções no processo de entendimento, descrição e previsão das ações do 'agente viável', i.e., aquele que indica um grau de importância considerável na ação de se preocupar com a comunicação de qualidade e seus vieses. Assim, o Quadro 2 apresenta um resumo das análises dos modelos segundo o fator de pertinência, a importância e a estratégia da comunicação.

Observa-se, portanto, que todos os modelos colocam os aspectos da comunicação como elementos implícitos e coadjuvantes à GC. Ao mesmo tempo, que esse achado é um ponto crítico, uma vez que a comunicação é essencial para que as pessoas exerçam seu trabalho com excelência nas organizações, ele oportuniza novas possibilidades para que sejam pensados modelos que consideram explicitamente os aspectos da comunicação. Isso significa que, não encontrado o trato explícito dos aspectos da comunicação, pode-se propor processos explícitos de comunicação voltados aos modelos consolidados da GC. Assim, no sentido de aprimorar a comunicação e, consequentemente, o conhecimento por eles gerenciado, o protagonismo da comunicação deve ser repensado e seus aspectos explicitamente apresentados por tais modelos.

Quadro 2 - Resumo dos aspectos analíticos dos modelos da GC

\begin{tabular}{|l|l|l|l|}
\hline \multicolumn{1}{|c|}{ Modelo } & $\begin{array}{c}\text { Fator de } \\
\text { pertinência }\end{array}$ & Importância da comunicação & Estratégia da comunicação \\
\hline $\begin{array}{l}\text { Von Krogh e } \\
\text { Roos (1995) }\end{array}$ & Baixa & $\begin{array}{l}\text { Evitar distorções que possam } \\
\text { comprometer o aprendizado } \\
\text { individual e organizacional. }\end{array}$ & $\begin{array}{l}\text { Comunicação ativa, i.e., enviada } \\
\text { para usuários específicos com } \\
\text { linguagem informal escrita e } \\
\text { verbal e, ainda que possibilite o } \\
\text { envio de artefatos multimídia. }\end{array}$ \\
\hline $\begin{array}{l}\text { Nonaka e } \\
\text { Takeuchi } \\
(1995)\end{array}$ & Baixa & $\begin{array}{l}\text { Evitar distorções } \\
\text { principalmente no } \\
\text { compartilhamento de } \\
\text { informações. }\end{array}$ & $\begin{array}{l}\text { Comunicação interativa com o } \\
\text { uso de canais interativos (e.g. } \\
\text { grupos de discussões no } \\
\text { WhatsApp) com uma linguagem } \\
\text { informal escrita e envio de }\end{array}$ \\
\hline
\end{tabular}

Perspectivas em Gestão \& Conhecimento, João Pessoa, v. 8, n. 2, p. 62-81, mai./ago. 2018. 


\begin{tabular}{|l|l|l|l|}
\hline Choo (2006) & Médio & $\begin{array}{l}\text { Evitar o comprometimento da } \\
\text { qualidade das decisões que são } \\
\text { tomadas a partir das } \\
\text { informações coletadas. }\end{array}$ & $\begin{array}{l}\text { Comunicação passiva com o uso } \\
\text { de linguagem formal tanto } \\
\text { verbal quanto escrita. }\end{array}$ \\
\hline Wiig (1993) & Médio & $\begin{array}{l}\text { Evitar a distorção na } \\
\text { informação que será } \\
\text { internalizada e contribuir para a } \\
\text { fidedignidade da descrição, } \\
\text { localização, captura, } \\
\text { distribuição e nova localização } \\
\text { do conhecimento. }\end{array}$ & $\begin{array}{l}\text { Comunicação interativa e ativa } \\
\text { com uma linguagem formal } \\
\text { tanto escrita quanto verbal. }\end{array}$ \\
\hline $\begin{array}{l}\text { I-Space de } \\
\text { Boisot (1998) }\end{array}$ & Alto & $\begin{array}{l}\text { Evitar que a codificação de } \\
\text { dados seja superficial e distante } \\
\text { da realidade. }\end{array}$ & $\begin{array}{l}\text { Comunicação interativa e ativa } \\
\text { com uma linguagem formal } \\
\text { tanto escrita quanto verbal. }\end{array}$ \\
\hline ICAS (2003) & Médio & $\begin{array}{l}\text { Evitar distorções no processo } \\
\text { de entendimento, descrição e } \\
\text { previsão das ações do agente } \\
\text { viável. }\end{array}$ & $\begin{array}{l}\text { Comunicação passiva e } \\
\text { interativa com linguagem } \\
\text { formal e verbal. }\end{array}$ \\
\hline
\end{tabular}

Fonte: Os autores (2017)

\section{CONCLUSÃO}

Os principais modelos da GC apresentam diferentes processos para a criação, o compartilhamento e o uso do conhecimento organizacional. Tais processos são dependentes das pessoas e, consequentemente, da boa comunicação entre elas para que um novo conhecimento possa ser gerado e utilizado pela organização. A qualidade da comunicação fazse então essencial nesses modelos. Dessa forma, este artigo teve como objetivo discutir aspectos relevantes da comunicação nos modelos da GC no sentido de refletir o papel da comunicação nesses modelos, estimulando assim novas pesquisas acerca do tema. Para tanto, foi realizada uma revisão da literatura e uma análise empírica dos principais modelos da GC e dos seus aspectos de comunicação.

Como resultado, observou-se que nenhum dos modelos da GC apresentam de forma explícita os aspectos dessa comunicação para que sejam evitados ruídos de comunicação e, assim, os modelos alcancem o seu principal objetivo, i.e, gerar conhecimento novo e útil para as organizações. Nessa dinâmica, é real a possibilidade do surgimento de ruídos que comprometam a qualidade da comunicação. Observou-se também que o nível de pertinência da comunicação para cada um dos modelos analisados apresentou-se de forma baixa, média e alta. Assim, com base na literatura, foram sugeridas estratégias de comunicação como forma de tentar mitigar esses ruídos, possibilitando a criação de conhecimento novo e útil. A ideia desses modelos da GC não apresentarem de forma explícita os aspectos da comunicação, não é suficientemente produtiva, tendo em vista que a comunicação realmente se faz presente de forma impactante e considera-se condição sine qua non que a forma como ela ocorre seja discutida e direcionada, com vistas a alcançar um nível de qualidade que possibilite sua efetividade dentro de qualquer um dos modelos da GC.

Finalmente, considerando o enfoque teórico acerca da importância da comunicação organizacional efetiva, fica evidente que há de se dar atenção à comunicação quando o assunto é a GC e seus modelos. Este artigo, assim, aponta a necessidade de se navegar por tal consideração para estimular mais pesquisas nesse sentido. Por isso, este artigo encoraja os

Perspectivas em Gestão \& Conhecimento, João Pessoa, v. 8, n. 2, p. 62-81, mai./ago. 2018. 
pesquisadores da área da GC em analisar e propor os processos de comunicação voltados aos modelos da GC, na tentativa de suprir essa lacuna que se apresenta de forma tão evidente. $O$ resultado de tais pesquisas pode contribuir para a construção de um novo modelo que aponte os aspectos da comunicação de forma explícita e, portanto, estimular ainda mais a implantação da GC nas organizações. Desse modo, este artigo deixa como contribuição os aspectos relevantes à comunicação para os modelos da GC com uma reflexão para o estímulo de novas pesquisas.

\section{REFERÊNCIAS}

AHMETI, F. HRM: Developing Organizational Communication Culture in Transitional Economies. European Scientific Journal, v. 10, n. 10, p. 301-312, abr. 2014.

ASHCRAFT, L. K.; ALLEN, B. J. The Racial Foundation of Organizational Communication. Communication Theory, v. 13, n.1, p. 5-38, 2003.

ALMEIDA, V. A Comunicação Interna na Empresa. Lisboa: Áreas Editora, 2003.

ANDRADE, I. A.; BERTI, D. W; TOMAÉL, M. I.; CORGOSINHO, R. J. M. Inteligência coletiva e ferramentas WEB 2.0: a busca da gestão da informação e do conhecimento em organizações. Perspectivas em Gestão \& Conhecimento, v. 1, n. Especial, p. 27-43, out. 2011.

BENNET, A. e BENNET, D. Designing the Knowledge Organization of the Future: The Intelligent Complex Adaptive System. In: HOLSAPPLE, C. W. (Org.). Handbook on Knowledge Management. Berlin, Heidelberg: Springer Berlin Heidelberg, 2003. p. 623-638.

BOISOT, M. H. Knowledge Assets: Securing Competitive Advantage in the Information Economy. New York: Oxford University Press, 1998.

CANONGIA, C; SANTOS, D.M; SANTOS, M.M; FORESIGHT; M. Inteligência Competitiva e Gestão do Conhecimento: instrumentos para a Gestão da Inovação. Gestão \& Produção, v.11, n.2, p.231-238, mai./ago. 2004.

CARDOSO, O. O. Comunicação empresarial versus comunicação organizacional: novos desafios teóricos. Revista de Administração Pública (RAP), Rio de Janeiro, v. 40, n. 6, p. 1123-1144, nov./dez. 2006.

CARVALHO, A. V.; PAULO, L.; SERAFIM, O. C. G. Administração de recursos humanos. 2. Ed. revista Vol. 2. São Paulo: Cengage Learning, 2014. 240 p.

CHENEY, G. Organizational Communication Comes Out. Management Communication Quarterly v. 21, n. 1, p. 80-91, ago. 2007.

$\mathrm{CHOO}, \mathrm{C}$. W. The Knowing Organization How organizations use information to construct meaning, create knowledge, and make decisions. New York: Oxford University Press, 1998.

Perspectivas em Gestão \& Conhecimento, João Pessoa, v. 8, n. 2, p. 62-81, mai./ago. 2018. 
The knowing organization: How organizations use information to construct meaning, create knowledge, and make decisions - 2nd ed. New York: Oxford University Press, 2006. 368 p.

CLARK, H. H. e BRENNAN, S. E. Grounding in communication. In: RESNICK, L.; LEVINE, J.; TEASLEY, S. (Org.). Perspectives on socially shared cognition. Washington: American Psychological Association, 1991. p. 127-149.

CRISTEA, D. S.; CAPATINA, A. Perspectives on knowledge management models. The Annals of “Dunarea de Jos", p. 355-366, 2009.

DALKIR, K. Knowledge Management in theory and practice. Burlington, MA: Elsevier, 2011.

DAVENPORT, T.; DE LONG, D.; BEERS, M., Successful knowledge management projects. Sloan Management Review, v. 39, n. 2, p. 43-57. 1998.

DRUCKER, P. F. The age of social transformation. Atlantic Monthly, v. 278, n. 5, p. 53-80, 1994.

FIALHO, F. A. P.; MACEDO M.; SANTOS, N.; MITIDIERI, T. C. Gestão do Conhecimento e Aprendizagem: As estratégias competitivas da sociedade pós-industrial. Florianópolis: Ed. Visual Books Ltda, 2006. 196 p.

GARICANO, L; WU, Y. Knowledge, Communication, and Organizational Capabilities. Organization Science, v. 23, n. 5, p. 1382-1397. 2012.

GOMES, A. D. Cultura Organizacional: Comunicação e Identidade. Coimbra: Editora Quarteto, 2000.

HOOF, B. V; RIDDER, J. A. Knowledge Sharing in Context: The influence of Organizational Commitment, Communication Climate and $\mathrm{CMC}$ use on Knowledge sharing. Journal of Knowledge Management, v. 8, n. 6, p. 117-130. 2004.

MALMELIN, N. Communication capital: Modeling coorporate communication as an organizational asset. Coorporate Communication, v. 12, n. 3, p. 298-310, 2007.

MUMBY, D. K. Internationalizing Organizational Communication: Linda Putnam's Legacy. Management Communication Quarterly, v. 26, n. 3, p. 498-504. 2012.

NONAKA, I. The knowledge-creating company. Harvard Business Review, v. 69, n. 6, p. 96-104, 1991.

NONAKA, I.; TAKEUCHI, H. The knowledge-creating company: How Japanese companies create the dynamics of innovation. Oxford: Oxford University Press, 1995.

Criação do Conhecimento na Empresa: como as empresas geram a dinâmica da inovação. Rio de Janeiro: Campus, 1997.

NORLYK, B. Management discourse: Talking the power walk in organizational communication. Language at Work - Bridging Theory and Practice v. 4, n. 6, ago. 2009.

Perspectivas em Gestão \& Conhecimento, João Pessoa, v. 8, n. 2, p. 62-81, mai./ago. 2018. 
RAMAL, A. C. Educação na Cibercultura: Hipertextualidade, Leitura, Escrita e Aprendizagem. Porto Alegre: Artmed, 2010.

PENTEADO, J. R. W. A técnica da comunicação humana -14a edição, revisada e ampliada. São Paulo: Cengage Learning, 2012. 496 p.

REGO, A. Comunicação Pessoal e Organizacional - Teoria e Prática - 4a ed. Lisboa: Edições Sílabo, 2016. 568 p.

RIBEIRO, S. A. N.; CALIJORNE, M. A. S.; JURZA, P. H.; ZIVIANI; F, NEVES; J. T. R. Gestão do conhecimento e desempenho organizacional: integração dinâmica entre competências e recursos. Perspectivas em Gestão \& Conhecimento, João Pessoa, v. 7, n. Especial, p. 4-17, mar. 2017.

PMI. A Guide to the Project Management Body of Knowledge. USA Project Management Institute, 2017. $589 \mathrm{p}$.

PEPULIM, M. E. H.; FIALHO, F. A. P.; SOUZA, R. P. L. Semiótica enquanto disciplina científica: uma ferramenta para uma comunicação eficaz. Perspectivas em Gestão \& Conhecimento, João Pessoa, v. 3, n. 2, p. 37-53, jul./dez. 2013.

SAITO, A; SANTOS, N. M. B. F. Gestão do conhecimento, eficiência e inovação. Perspectivas em Gestão \& Conhecimento, João Pessoa, v. 7, n. Especial, p. 1-3, mar. 2017.

SANTOS, T. C. S; TRZECIAK, D. S; RADOS, G. V. Narrativa no fluxo de informação para o compartilhamento de conhecimento em MPE: proposta de um modelo. Perspectivas em Gestão \& Conhecimento, João Pessoa, v. 7, n. 1, p. 28-47, jan./jun. 2017.

STEFANO, N. M.; CASAROTTO F. N.; Freitas, M. C. D.; MARTINEZ, M. A. T. Gestão de Ativos Intangíveis: Implicações e Rela,ções da Gestão do Conhecimento e Capital. Perspectivas em Gestão \& Conhecimento, v. 4, n. 1, p. 22-37. 2014.

STEWART, T. A. Capital Intelectual. São Paulo: Editora Campus, 1998.

SCHOENEBORN, D. The Pervasive Power of PowerPoint: How a Genre of Professional Communication Permeates Organizational Communication. Organization Studies, v. 34, n. 12, p. 1777-1801, dez. 2013.

TAKEUCHI, H.; NONAKA, I. Gestão do conhecimento. Porto Alegre: Bookman, 2008. 320p.

TAVARES, M. Comunicação Empresarial e Planos de Comunicação: Integrando teoria e prática. São Paulo: Editora Atlas, 2007. 228 p.

VELLOSO, J. P. R. (Org). Reforma Política e Economia do Conhecimento: Dois Projetos Nacionais. Rio de Janeiro: Editora José Olympio, 2005. 234 p.

VON KROGH, G. V.; ROOS, J. Organizational Epistemology. New York: St. Martin's Press, 1995. VON KROGH, G.; NONAKA, I.; ICHIJO, K. Develop knowledge activists! European Management Journal v. 15, n. 5, p. 475-483, out. 1997.

Perspectivas em Gestão \& Conhecimento, João Pessoa, v. 8, n. 2, p. 62-81, mai./ago. 2018. 
WILLERDING, I. A. V.; KRAUSE, M. G.; LAPOLLI, E. M. Gestão de Pessoas e Gestão do Conhecimento à luz da Estética Organizacional. Perspectivas em Gestão \& Conhecimento, v. 6, n. 1, p. 141-154, 2016.

WIIG, K. M. Knowledge Management Foundations, Thinking How- People and Organizations Create, Represent, and Use Knowledge. Arlington: Schema, 1993. 